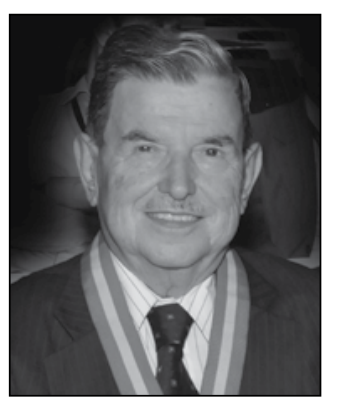

\title{
Efraím Otero Ruiz (1931-2014)
}

\section{Académico multifacético}

Nació en Bucaramanga el 11 de noviembre de 1931 y estudió con los padres jesuitas en los colegios San Pedro Claver de Bucaramanga y San Bartolomé La Merced de Bogotá. Sus estudios médicos los realizó en la Universidad Javeriana, egresando en 1953 y graduándose con una tesis laureada titulada "Uso clínico de los isótopos radiactivos. Primeras aplicaciones en Colombia”.

La trayectoria del académico Otero fue muy conocida. Después de hacer pinitos en anestesiología, su interés se orientó hacia los isótopos radiactivos a raíz de su vinculación al Instituto Nacional de Cancerología. Posteriormente viajó a los Estados Unidos, donde completó su entrenamiento en endocrinología y medicina nuclear en Columbia University, en el Donner Laboratory de la Universidad de California (Berkeley) y en el Oak Ridge Institute of $\mathrm{Nu}$ clear Studies, entre 1957 y 1970. Como consultor de la Comisión Americana de Energía Atómica basada en Oak Ridge, dirigió entre 1965 y 1971, los cursos de medicina nuclear que se dictaron en 8 países de Centro y Suramérica, esfuerzo que le mereció la ciudadanía honoraria del estado de Tennessee. Después en el Instituto, a su regreso a Bogotá, fue Jefe de la Sección de Radioisótopos y dirigió el Departamento de Investigaciones. Otero fue uno de aquellos primeros endocrinólogos colombianos, que desde la medicina nuclear hicieron significativos aportes al estudio de la glándula tiroides. En 1960 vio la luz su citada publicación en Nature sobre TSH, donde figuraron como coautores profesores de la talla de Sidney Werner y de Seegal. Con su grupo del Cancerológico, en compañía de Jaime Cortázar, Jaime Ahumada y otros colegas, hizo estudios pioneros sobre tratamiento del cáncer de tiroides con yodo radiactivo, sobre gamagrafías de dicha glándula y acerca del uso de isótopos radiactivos en otras patologías. Su experiencia de aquellos años pioneros la recogió en su obra "Medicina Nuclear, Temprana Historia y Reminiscencias Personales". Publicó varios de sus artículos en la "Revista de la Sociedad Colombiana de Endocrinología”, en cuya colección podemos todavía leerlos. En tiempos posteriores, su interés clínico lo dedicó con preferencia al estudio y tratamiento de la obesidad.

$\mathrm{Su}$ nombramiento como Director de Colciencias (cargo que ocupó entre 1972 y 1983) generó un cambio en sus publicaciones que se encaminaron más hacia las políticas públicas en ciencia y tecnología. En 1963 -cuando editaba yo la revista Universitas Medica de la Javeriana- tuve el gusto de publicar su primer artículo sobre historia de la medicina, una biografía del famoso tiroidólogo de Harvard James Howard Means; por aquella época me asesoró también en nuestra tesis de grado sobre autoinmunidad tiroidea. Fue notoria su influencia en la especialidad, destacándose por sus actividades en la Asociación Colombiana de Endocrinología, Diabetes y Metabolismo, donde fue varias veces su presidente y miembro honorario. Su presencia en congresos nacionales e internacionales como conferencista, en mesas redondas o como directivo, será siempre recordada.

Como autor de 300 publicaciones entre investigaciones, revisiones, editoriales, prólogos, comentarios, discursos, artículos de reflexión, además de sus ocho libros — dos de ellos en gran formato- su producción refleja lo amplio de sus intereses intelectuales y lo profundo a lo que pudo llegar con ellos. Al retirarse de Colciencias, coronó su vida pública como Ministro de Salud de la administración Betancur.

Su entusiasmo por las letras se observa en la lectura de sus libros poéticos, en sus innumerables prólogos y comentarios académicos. Estudioso lector, acumuló un buen número de obras selectas en su biblioteca personal. Además de Editor de la revista Medicina de la Academia (y recientemente su Editor Emérito), lo fue también a dos manos con el académico José Félix Patiño, de la inolvidable Tribuna Médica. De versátil pluma, tuvo éxito en los versos y en la prosa, ganando un premio internacional de Tanatocuentos. "Cuasi una Fantasía" recoge momentos especiales con médicos destacados en la vida nacional. Fue traductor de versos de poetas ingleses y norteamericanos y escribió un libro biográfico sobre el historiador, traductor y crítico literario Enrique Uribe-White, titulado "Santa Eulalia, memorias de una casa abierta". Su libro "Versos Melánicos" tuvo buena acogida. Esto le llevó a la Academia Colombiana de la Lengua, donde llegó a ser Miembro de Número.

El interés por la historia lo llevó a escribir cierto número de libros con notas autobiográficas, que recogen su experiencia y conocimientos sobre medicamentos, medicina nuclear y "Setenta años de cáncer en Colombia" (sobre la primera etapa del Instituto Nacional de Cancerología), concretando además estas actividades en la Sociedad Colombiana de Historia de la Medicina (fundador y presidente), la Academia Colombiana de Historia (Miembro de Número) y la Real Academia de Historia (Miembro Correspondiente).

Fue miembro de la Academia Nacional de Medicina por más de cuatro décadas, presidente de la institución (1990-1992), coordinador de la Comisión de Publicaciones y miembro honorario. Perteneció a varias sociedades científicas nacionales e internacionales y fue presidente y magistrado del Tribunal de Ética Médica.

Su febril actividad le mereció recientemente otro lauro académico, el de miembro honorario de la Academia Colombiana de Ciencias Exactas, Físicas y Naturales. En él se conjugaron entonces los ideales de humanismo, ciencia y medicina.

Efraím Otero Ruiz perteneció a una élite de intelectuales colombianos. Su matrimonio con Gloria Leongómez de Otero deja cinco hijos sobresalientes en sus diferentes actividades (dos de ellos médicos especialistas) además de varios nietos. Tuvo numerosos amigos, contertulios y conocidos, entre los que me conté desde aquellas recordadas épocas de estudios universitarios. La sociedad colombiana, el cuerpo médico y nuestra sexagenaria Asociación, pierden un valioso elemento.

Alfredo Jácome Roca*

*Internista-Endocrinólogo. Miembro de Número, Academia Nacional de Medicina y Colegio Americano de Médicos. Miembro Honorario y Ex Presidente, Asociación Colombiana de Endocrinología, Diabetes y Metabolismo. 